\title{
Um olhar Nietzschiano à Dogville: as desordens morais da personagem Grace no discurso fílmico
}

\author{
A Nietzschian Look of a Dogville: \\ the Moral Disorders of the Character Grace in the Filmic Discourse \\ Una Mirada Nietzschiano a Dogville: \\ los Desórdenes Morales del Personaje Grace en el Discurso Fílmico \\ Cintia Moletal \\ Fábio Hansen ${ }^{2}$
}

\begin{abstract}
Resumo
O presente artigo tem como objeto de pesquisa o filme Dogville, de 2003, e buscou responder à seguinte questão: como se dá a aproximação entre o discurso sobre a moral em Dogville e as considerações sobre a moral de Nietzsche, tendo em vista o comportamento da personagem Grace no discurso fílmico? Para respondê-la, os objetivos foram analisar a construção do discurso sobre a moral em Dogville, relacionando-o às considerações sobre a moral de Nietzsche; e identificar as desordens morais na tomada de posição da personagem Grace de acordo com os valores que manifesta no filme. Para alcançar tais propósitos, foi utilizada a abordagem teórico-metodológica da análise do discurso de linha francesa, com os conceitos de interdiscurso, formação discursiva e posição-sujeito, que evidenciam, com eles, as desordens morais que constituem o comportamento da protagonista no filme. Dessa maneira, deslizou-se o sentido moral da obra, que revelou um sujeito contemporâneo ambíguo e fragmentado.
\end{abstract}

Palavras-chave: Dogville. Moral. Análise do Discurso. Nietzsche. Cinema.

\begin{abstract}
The present article has as its object the research of the film Dogville, 2003, and aims to answer the following question: how does the discourse about moral in Dogville and Nietzsche's moral considerations come together in view of the behavior of the character Grace in film speech? In order to answer it, the objectives were to analyze the construction of the discourse on the moral in Dogville, relating it to the considerations on the moral of Nietzsche; and identify the moral disorders in the positioning of the character Grace according to the values that she manifests in the film. In order to achieve these objectives, the theoretical-methodological approach of French line discourse analysis was used, with the concepts of interdiscourse, discursive formation and subject-position, wich demonstrate, with them, the moral disorders that constitute the behavior of the protagonist in the film. In this way, a moral sense of the work changes, which reveals an ambiguous and fragmented contemporary subject.
\end{abstract}

Keywords: Dogville. Moral. Speech analysis. Nietzsche. Movie theater.

\footnotetext{
${ }^{1}$ Mestra em Comunicação pela Universidade Federal do Paraná. Curitiba (PR). e-mail: cintiamoleta@gmail.com.

${ }^{2}$ Doutor em Letras pela UFRGS. Professor permanente no Programa de Pós-Graduação em Comunicação (PPGCOM UFPR) na linha de pesquisa Comunicação, Educação e Formações Socioculturais, Curitiba (PR). email: fabiohansen@yahoo.com
} 


\section{Resumen}

El presente artículo tiene como objeto de investigación la película Dogville, de 2003, y buscó responder a la siguiente pregunta: ¿cómo se da el acercamiento entre el discurso sobre la moral en Dogville y las consideraciones sobre la moral de Nietzsche, teniendo en vista el comportamiento de la mujer personaje Grace en el discurso fílmico? Para contestarla, los objetivos fueron analizar la construcción del discurso sobre la moral en Dogville, relacionándolo a las consideraciones sobre la moral de Nietzsche; e identificar los desórdenes morales en la toma de posición del personaje Grace de acuerdo con los valores que manifiesta en la película. Para alcanzar tales objetivos, se utilizó el enfoque teórico-metodológico del análisis del discurso de línea francesa, con los conceptos de interdiscurso, formación discursiva y posición-sujeto, que evidencian con ellos los desórdenes morales que constituyen el comportamiento de la protagonista en la película. De esa manera, se desliza un sentido moral de la obra que revela un sujeto contemporáneo ambiguo y fragmentado.

Palabras clave: Dogville. Moral. Análisis del Discurso. Nietzsche. Cine.

\section{INTRODUÇÃO}

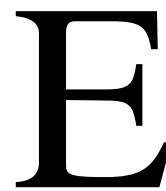

m decorrência de desordens morais, a fictícia cidade de Lars von Trier Dogville - foi dizimada a mando de gângsteres, que obedeciam ao pedido de sua sublíder, Grace. Depois de provar-se um exemplo de ética e resignação

frente ao sofrimento que lhe foi imposto, a protagonista "muda de ideia" em relação ao vilarejo e seus habitantes, passando de vítima a algoz e destinando seus quinze residentes a um desfecho fatal.

Tal instabilidade de comportamento, principalmente no que diz respeito à sua sujeição "irrefletida" e posterior posicionamento reverso, é o cerne desse artigo, que se pauta no discurso fílmico de von Trier para uma reflexão sobre a moral tradicional da sociedade ocidental e aos valores que nela se legitimam. Essas reflexões são um recorte da dissertação de mestrado intitulada "Quando Dogville mostra os dentes: o efeito-leitor e as desordens morais no discurso fílmico de Lars von Trier", cujo objetivo foi compreender como o efeitoleitor produz efeitos de sentido sobre a moral no discurso fílmico de Dogville.

Ao repensar sua conduta e partir de atitudes criminosas, Grace instiga o espectador de Dogville a questionar-se sobre os fundamentos dos princípios que regem nossas relações, refletindo insegurança sobre a validade e necessidade dos valores que alicerçam a vida humana. Dadas desordens morais emanam da narrativa e dela se extravazam, propondo um repensar a partir de nosso ponto de vista da existência, de seus padrões e suas "normalidades".

Questionamentos como esses que o filme nos possibilita condizem com os postulados da filosofia de Nietzsche, principalmente no que diz respeito à moral e aos valores. Como um crítico da moral, o filósofo alemão do século XIX, ao partir de sua desaprovação do 
cristianismo e sua contrariedade frente aos dogmas dessa religião, indaga-se sobre a validade dos valores e contesta sua necessidade, alegando seu caráter de domesticação e de dominação da natureza do ser. Para o filósofo, ser ético é prestar obediência e submeter-se às regras sociais previamente estabelecidas. Tais regras morais constituem tudo aquilo que é feito por hábito, costume ou tradição (NIETZSCHE, 2005).

Olhando para a filosofia niilista, buscamos compreender como são constituídos esses valores e como eles são retratados em Dogville, podendo indicar, pela delimitação de um "padrão", uma moral tradicional e quais são os saberes discursivos que a ela pertencem. Tomando essa perspectiva, estabelecemos nosso recorte analítico a partir de Grace e sua desordem moral, visando interpretar sua mudança de comportamento.

Atingir esse propósito é possível ao aproximar tal análise da abordagem teóricometodológica da análise do discurso francesa (AD), utilizando os conceitos de interdiscurso, formação discursiva e posição-sujeito. Essa vertente, que tem Michel Pêcheux como seu principal representante, é o que dá suporte para a análise ao considerar os diferentes efeitos de sentido que podem ser atribuídos ao discurso fílmico. Como refere Orlandi (2015, p. 7), a AD permite "(...) problematizar as maneiras de ler, levar o sujeito falante ou leitor a se colocarem questões sobre o que produzem e o que ouvem nas diferentes manifestações da linguagem". Essa aproximação teórica exige cautela, principalmente no que tange a associar a abordagem materialista (discursiva) ao viés niilista da filosofia; pois, enquanto para a primeira o sujeito é sempre (em algum grau) assujeitado, para Nietzsche, o indivíduo tem a possibilidade de libertar-se dos valores morais (enquanto que para a AD essa liberdade é apenas um efeito).

Partindo dessas vertentes, temos como questão norteadora desse artigo: como se dá a aproximação entre o discurso sobre a moral em Dogville e as considerações sobre a moral de Nietzsche, tendo em vista o comportamento da personagem Grace no discurso fílmico? Para respondê-la, nossos objetivos para esse artigo são analisar a construção do discurso sobre a moral em Dogville, relacionando-o às considerações sobre a moral de Nietzsche; e identificar as desordens morais na tomada de posição da personagem Grace de acordo com os valores que manifesta no filme.

A análise nos revela, dessa maneira, que as desordens morais percebidas no comportamento da protagonista se deslocam do sujeito fictício para uma reflexão sobre a atualidade: qual a validade de valores preestabelecidos na pós-modernidade? Ao examinar a conduta de Grace diante de um contexto de valores ambíguos, colocamos em evidência o sujeito fragmentado, em conflito, que é preconizado pela base psicanalítica da $\mathrm{AD}$, e que 
representa o sujeito pós-moderno, marcado pela transitoriedade e pela presença de uma lógica baseada na reversibilidade, que se assujeita a um código ético contraditório, tensionando os saberes legitimados nas e pelas estruturas sociais.

\section{O DISCURSO SOBRE A MORAL TRADICIONAL}

O dizer não é propriedade do sujeito. Considerando tal afirmação de Orlandi (2015), voltamos nosso olhar para o discurso sobre a moral, visando compreender como ele se constitui a partir das diversas vozes, do já dito, do que pode ou deve ser dito, que implicam em sua formulação e seus sentidos. É preciso, para tanto, recorrer às noções de $\mathrm{AD}$ de interdiscurso e formação discursiva (FD), para perceber esses dizeres (outros) que se relacionam a uma ideologia dominante sobre a moral.

Considera Orlandi (2015, p.29) que "interdiscurso é o que fala antes, em outro lugar, independentemente. Ou seja, (...) o saber discursivo que torna possível todo dizer e que retorna sob a forma do pré-construído, o já-dito que está na base do dizível sustentando cada tomada da palavra". Para Indursky (2013, p.45), o interdiscurso "é o lugar de formação do pré-construído, funcionando como um elemento regulador do deslocamento das fronteiras de uma formação discursiva, controlando sua reconfiguração (...)".

O interdiscurso é sempre pensado em relação à formação discursiva (FD) e essa, em relação à formação ideológica. De acordo com Pêcheux e Fuchs (2014), é por meio desse conjunto complexo chamado formação ideológica que a ideologia atua, interpelando os indivíduos em sujeitos. Para compreender o sentido de um discurso - nesse caso, o discurso sobre a moral -, é preciso remetê-lo a uma formação discursiva: dependendo da formação ideológica a que a palavra "moral" esteja submetida, há um sentido e esse sentido pode ser outro em uma diferente FD. Um comportamento tido como de acordo com a moral em nosso país, pode ter significados distintos nos diversos países. Ainda, um comportamento moral de uma região, na década de 1930, pode revelar alguns costumes diferentes do que os atuais. Essas mudanças são de ordem sócio-cultural-histórica, temporal e, consequentemente, ideológica, de acordo com os muitos outros discursos (interdiscurso) que constituem o discurso sobre a moral em dada FD.

Uma FD hegemônica em relação à moral é, portanto, aquela que suporta os valores regras, hábitos, costumes - instituídos em determinada sociedade. Chamaremos essa FD de moral tradicional, pois ela tange esse sistema de valores instituídos, que conduz e direciona as ações humanas. Indicar um sujeito interpelado pela FD tradicional é considerá-lo como parte desse sistema, que assume e vivencia os valores pelo hábito e pelo zelo aos costumes. 
Um importante crítico dos valores e "oponente" dos valores morais que no século XIX contestava sua validade era o filósofo Nietzsche, voz que, anos depois, ainda ecoa como uma necessária crítica ao nosso modo de vida, ao entregar-se natural e cegamente a essa camisa de força social que são os valores. Ao pensar em uma crítica filosófica à moralidade, alega Nietzsche (2013, p. 34) que ela "não é outra coisa senão a obediência aos costumes sejam eles quais forem; ora, os costumes são a maneira tradicional de agir e de avaliar". Para o autor (2013, p.35), a tradição se constitui em "uma autoridade superior à qual se obedece", por meio de um temor (supersticioso) a um poder incompreensível e indefinido. É como o animal domesticado, que é treinado para conter seus instintos e obedecer a uma autoridade superior que pode lhe fazer mal (castigar). No caso da moral, essa autoridade perpassa o controle social, mas recai ao próprio entendimento pela base cristã/metafísica dos valores morais.

Uma FD da moral tradicional é permeada por uma ideologia de múltiplos valores, hábitos, tradições, costumes, regras socialmente impostas ou aceitas. A noção sobre tais regras não é inerente ao ser, mas uma construção histórico-social, que aprendemos/reformulamos durante a vida pela incorporação de novos/diferentes saberes da forma-sujeito.

Há, contudo, vários discursos (outros) que atravessam, reconfiguram, transformam o discurso da FD da moral tradicional. O mais representativo deles, que fundamentam, historicamente, a base dos saberes dessa FD, é tratado dessa maneira por Nietzsche (1998), para o qual nossa moral ocidental contemporânea é pautada essencialmente no discurso religioso cristão, que subverteu as noções de bem e mau por meio da figura de Cristo e da construção ideológica cristã, que baseia os valores em um refinamento do espírito que leva o ser à plenitude em uma vida pós-terrena.

O filósofo elabora esse argumento em sua obra A Genealogia da Moral, de 1887, na qual considera que buscar a origem dos valores morais é também buscar a origem dos conceitos de "bem" e "mal". Alega que, inicialmente, o sentido de "bom" remetia à nobreza, aos poderosos, que atribuíam a si e aos seus atos como bons, tomando o "direito" de criar e dar nome a valores, enquanto "ruim" era tudo o que remetia à plebe, à pobreza, à simplicidade. No entanto, em algumas sociedades, a alta classe social era sacerdotal, o que ocasionava um modo de valoração diferente - e até oposto - àquele "cavalheirescoaristocrático". Enquanto estes estimavam sua constituição física e saúde, bem como apreciavam a guerra, aventura, caça, dança, torneios - atividades livres, contentes - os sacerdotes, afirma Nietzsche (1998, p.24-25), eram figuras odiosas e vingativas. 
O filósofo vê, a partir disso, como ícone dessa inversão de valores a figura Jesus Cristo, considerando-o como uma isca de "irresistível sedução" para o "refinamento do espírito" (NIETZSCHE, 1998, p.28). Para ele, é por meio desse discurso religioso cristão que o homem nega sua natureza e se afasta dos instintos, passando a agir em prol de seu doutrinamento. "O que é mais prejudicial do que qualquer vício? A compaixão ativa para com todos os deficientes e fracos; o cristianismo" (NIETZSCHE, 1996, p.28).

Este é o mais elucidativo dos diversos discursos dispersos no discurso sobre a moral: não é preciso que o sujeito seja religioso e cristão para que se aproprie de seus sentidos. Não é preciso, por exemplo, que creia em Deus ou em céu/inferno para que seja altruísta e tenha esperança de uma vida após a morte; também não é preciso que seja cristão para que tenha má consciência diante das faltas que considera ter cometido, como forma de punição. Pensa, portanto, ser fonte do seu dizer e ter controle dos sentidos ao enunciar um discurso sobre a moral, esquecendo-se dessa relação entre o já-dito e o que se está dizendo.

Com isso, ao refletir sobre os valores tradicionais que permeiam o contexto do filme Dogville, é preciso ponderar o lugar em que a história se passa, a época e o modo de vida das pessoas ao observar como se vestem, se comportam, se comunicam. Isso suscita em nós um imaginário sobre a moral hegemônica da época (que não se difere em muito da nossa atualidade), sobre o que pode ou deve ser dito dentro dessa FD, o que é, na maioria das vezes, circunstancial, dada sua característica de ambiguidade.

O sujeito pode, dessa maneira, identificar-se com alguns saberes e contra-identificar-se com outros, sem necessariamente desvincular-se da formação ideológica em questão. Nesse sentido, Indursky (2013, p.45) afirma que "uma FD é uma unidade dividida e heterogênea. Seu contorno é fundamentalmente instável, pois não há limites rígidos a separar os elementos internos de seu saber daqueles que lhe são externos". Há alguns valores, entretanto, que são imprescindíveis no saber dessa forma-sujeito, alguns dos quais podemos apontar, tendo como base a Filosofia nietzschiana: altruísmo, compaixão, respeito ao próximo, doação, fé, esperança, caridade, amizade, trabalho, relações familiares, obediência à lei e à justiça, desapego aos bens materiais, educação, ciência, culpa. Esses saberes, na perspectiva da AD, alguns dos quais serão percebidos pelas materialidades fílmicas a serem apresentadas na sequência, caracterizam a FD de moral tradicional e revelam uma postura ética e de princípios do sujeito que a ela se assujeita.

É com esse conjunto de saberes tradicionais que Grace se identifica até dado momento do filme, caracterizando o que chamamos de "boa Grace". No entanto, ao sucumbir à 
vingança e à penalização dos habitantes da cidade, desliza dessa posição, caracterizando o sujeito ambíguo preconizado pela $\mathrm{AD}$ e revelando as fluidas fronteiras de uma FD. Nosso propósito é reconhecer seu assujeitamento a essa formação discursiva e ideológica referente à moral tradicional, bem como interpretar sua posição-sujeito ao manter-se como uma pessoa resignada e, posteriormente, ceder a um desejo de punição, levando a questionamentos sobre a validade dos valores e sobre o sentido de ser "bom" ou "ruim" dentro dessa FD.

\section{A "BOA" GRACE NO DISCURSO FÍLMICO DE DOGVILLE}

Grace chega à Dogville fugida de gângsteres, após um morador da cidade, Tom (a pessoa de quem ela mais se aproxima na história) escutar alguns tiros nas proximidades. Sem revelar ou dar explicações sobre as razões de tal perseguição, a protagonista demonstra medo e angústia frente àqueles que passamos a ver, provisoriamente, como seus carrascos.

As dúvidas que sua fuga suscita são aplacadas pelo comportamento honesto e retidão de caráter que a jovem demonstra em sua jornada na cidade. Sua resignação frente às intempéries, somada à finita incapacidade de vingança, raiva ou má ação motivada por seu sofrimento, refletem o comportamento moral da protagonista, ou seja, o conjunto de valores e normas sociais que ela valida ao assumi-las para si, discursos-outros dos quais se apropria. Assim é que se dá o seu assujeitamento à FD de moral tradicional, por meio de seu comportamento ético, alinhado aos padrões morais.

Para evidenciar tal afirmação, separamos algumas materialidades do filme, nas quais podemos perceber sua conduta morigerada, de conformidade às regras vigentes, como a cena em que Grace e Tom conversam, na casa do rapaz, sobre as atitudes da moça e as razões de sua fuga. Nessa conversa entre eles, Grace menciona a Tom, na sequência discursiva 1 (SD1), que precisa se policiar para não ser arrogante, atitude que precisou ensinar a si mesma.

SD1: (Grace) Fui criada para ser arrogante. Então tive que me ensinar essas coisas.

Na visão da jovem, ser arrogante é algo que não pertence à forma-sujeito da moral tradicional, e é por isso que ela deve se afastar dessa atitude e comportar-se de maneira humilde, reafirmando-se como um ser de princípios. Essa tomada de posição dentro da FD que denominamos de moral tradicional, nos leva a refletir acerca de algumas críticas nietzschianas sobre a moralidade, visando entender a manifestação dos saberes morais na 
protagonista e sua "necessidade" de não ser arrogante. Para o filósofo (2005, p.67), ser moral "significa prestar obediência a uma lei ou tradição há muito tempo estabelecidas." Dessa maneira, o ser que age conforme a moral é tido como bom (não necessariamente como bom em si, mas bom para algo), pois segue valores como a benevolência, compaixão, altruísmo; enquanto seu oposto, o ser mau, é aquele imoral, que resiste à tradição, seja ela qual for. Nessa perspectiva nos referimos a esse primeiro momento de Grace no filme como boa (assujeitada à FD de moral tradicional), que na definição de Nietzsche é aquela que segue a tradição.

É preciso considerar, ainda, a ponderação do filósofo sobre tais juízos de valor, quando afirma (2005, p.68) que "'egoísta' e 'altruísta' não é a oposição fundamental que levou os homens à diferenciação entre moral e imoral, bom e mau, mas sim estar ligado a uma tradição, uma lei, ou desligar-se dela". A moral não é, dessa maneira, uma manifestação individual, mas tem seu significado comum, no coletivo, principalmente porque não escolhemos nossos próprios valores. Foi decidido, em algum momento histórico, que aquela conduta traria algum bem para a humanidade e que seria mais fácil viver de tal maneira, tornando até os mais duros costumes, agradáveis com o tempo (NIETZSCHE, 2005).

O indivíduo se beneficia a partir de tais padrões de comportamento da instituição moral - afirma Nietzsche (2005) que fazemos melhor o que nos é habitual, sentindo, até mesmo, prazer. Para o autor (2013), esse prazer também está ligado à sedução que tal instância tem na nossa vida - ela sabe entusiasmar. Isso porque sabemos que o costume já foi comprovado e por isso deduzimos que é proveitoso: uma união do útil ao agradável.

Na teoria nietzschiana, esse sujeito mordido pela tarântula moral é o que o filósofo chama de espírito cativo (ou dependente), aquele que vive conforme a moral do seu tempo, sujeitando-se à tradição e aos costumes. Eles são a regra, o comum - não viver como um espírito cativo seria a exceção (o espírito livre). Para o autor (2005, p.145-146), "a estreiteza de opiniões, transformada em instinto pelo hábito, leva ao que chamamos de força de caráter. (...) Ao indivíduo de caráter forte falta o conhecimento das muitas possibilidades e direções da ação; seu intelecto é estreito, cativo (...)".

A FD moral que chamamos de tradicional é a que se relaciona a esse modo de ser cativo, que "empresta" das várias outras vozes (discursos) a regência de seu modo de viver: daquele que vive conforme as ações habituais, que foram previamente aceitas, aprovadas, para assim vincular-se a uma comunidade e cultura; daquele que aceita o que é tradicional sem buscar razões, mas o faz por rotina e por aceitação das normas sociais; daquele que cultiva 
valores metafísicos, pautados na fé de que suas ações são boas, sem refletir sobre a quem elas favorecem e por quê; daquele que se sacrifica pelos costumes e confunde com prazer esse "ganho psicológico" do fazer o habitual.

Para tal reflexão é preciso considerar, como postula a $\mathrm{AD}$, que o sujeito também não é dotado de unicidade. Como um ser em falta, há nele o furo do equívoco, da contradição, do inconsciente, que o constituem em um ser fragmentado e dotado de ambiguidade - assim refere Ferreira (2004, p.40):

Se não houvesse a falta, se o sujeito fosse pleno, se a língua fosse estável e fechada, se o discurso fosse homogêneo e completo, não haveria espaço por onde o sentido transbordar, deslizar, desviar, ficar à deriva. A falta é, então, tanto para o sujeito quanto para a língua, o lugar do possível e do impossível (real da língua).

O ser em falta que é o sujeito é o que possibilita que Grace mude de ideia ao final do filme. Entretanto, sua posição é de pleno assujeitamento na maior parte do enredo, remetendo à FD de moral tradicional. Em outro diálogo na mesma cena (da conversa entre Grace e Tom), podemos novamente perceber um momento de culpabilização em que a jovem se coloca, refletido na SD2, quando refere uma falha em seu comportamento ao furtar o osso do cachorro (Moisés) para utilizar em sua defesa, logo que chega à Dogville:

SD2: (Grace) Não mereço esse pão. Eu roubei aquele osso. Eu nunca havia roubado nada. E agora tenho que me punir.

Tal discurso é proferido quando Tom oferece comida à jovem, que inicialmente rejeita o auxílio por não se considerar merecedora e por acreditar que precisa de uma punição. Esse autojulgamento é implícito em suas palavras, quando relaciona o desmerecimento ao roubo, algo que não pertence aos saberes da forma-sujeito da FD de moral tradicional.

Ela demonstra, com isso, esse sentimento de culpa, algo profundamente arraigado e bem visto no discurso sobre a moral. Nietzsche (1998) estabelece, em sua genealogia da moral, um entendimento sobre a noção moral da culpa, que relaciona ao conceito material de "dívida" pela instituição de um castigo como uma reparação a um dano sofrido. Afirma o autor que, na história da humanidade, o castigo aplicado a um criminoso não diz respeito a uma obrigação de punição a quem cometeu a falta, mas serve para que quem se sentiu prejudicado possa descarregar seu ódio pelo castigo ao outro. Dessa maneira, alega que "qualquer dano encontra o seu equivalente e pode ser realmente compensado, mesmo que seja 
com a dor do seu causador", revelando sua ideia de equivalência entre dano e dor, em uma relação entre credor e devedor (1998, p.48).

Para Nietzsche (2005), a culpa é um estado do indivíduo moralizado, oriunda do dever e do sentimento de obrigação para alguma coisa. Diante do erro, o indivíduo sente-se culpado, em dívida, e alia esse pensamento à memória (psicológica, reminiscência), ou seja, à dificuldade de esquecer a ofensa que praticou e que, assim como Grace, precisa aplicar-se uma punição para que sua dívida de ordem moral (culpa) seja aliviada.

A má consciência é herança do pensamento cristão, que alcança seu estado máximo a partir da ideia de que há um Deus que perdoou todos os nossos pecados e que torna-se nosso "credor" - não há mais uma dívida material a ser paga, então esse sentimento de falta volta-se para o homem por meio do sofrimento imposto pela má consciência. Nisso reside seu arrependimento, sua culpa pelo que considera serem suas falhas morais. "O que é moral cristã? O acaso roubado de sua inocência, a desgraça manchada pelo conceito de 'pecado', o bem-estar como perigo, como 'tentação'; a indisposição fisiológica envenenada pelo verme da consciência...." (NIETZSCHE, 1996, p.47).

É nesse sentido que Grace mede o seu "merecimento": como julga ter cometido um erro, precisa, de alguma maneira, sacrificar-se por ele, seja por sua culpa cristã, seja pela pena física de passar fome. Em cada um desses sentidos, há a ideia referida por ela de punição, por meio da qual há a quitação da dívida e, na falta de um credor que realize essa cobrança, ela é feita pela má consciência da jovem.

Essa é uma atitude característica do espírito cativo, do ser do rebanho, que aprendeu (habituou-se, treinou-se) a sentir remorso diante do que considera ser uma má ação, uma conduta imoral. Percebe-se nessa tomada de posição a ausência de razões, de questionamentos sobre a culpa autoimplicada - por que é necessária? A quem estou prejudicando? A punição repara o dano causado? O dano é real? Mas o espírito cativo não é dado a razões, mas ao hábito. Como afirma Nietzsche (2005, p. 144) "O espírito cativo não assume uma posição por esta ou aquela razão, mas por hábito (...). Habituar-se a princípios intelectuais sem razões é algo que chamamos de fé".

Assim também o sujeito da $\mathrm{AD}$ não é totalmente consciente e livre em suas escolhas, mas interpelado por seu assujeitamento ideológico, passando a agir conforme sua posição e sua identificação à FD. Nisso consiste seu hábito - operar de acordo com o que pode e deve ser dito a partir do sujeito do saber da formação ideológica. Por isso, quando dizemos que 
Grace escolhe a punição para quitar sua dívida, essa escolha não é nem tão livre nem tão consciente, mas é feita de acordo com sua posição dentro da FD.

Tal postura de Grace dentro da FD de moral tradicional relaciona-se à noção de posição-sujeito. É esse conceito que assegura a existência de outras tomadas de posição dentro de uma FD, que não correspondem a um lugar empírico do discurso, mas referem-se à identificação e assujeitamento à dada formação ideológica.

Dessa maneira, quando o sujeito enunciador encontra o sujeito do saber em uma FD, estabelece-se entre eles uma relação de posição-sujeito (INDURSKY, 2013). A resignação da protagonista, sua obediência desmedida, misericórdia e compaixão manifestada (até certo ponto da história), a colocam na que consideramos a posição-sujeito 1 (PS1), que nomeamos como "sacrifício aos costumes", identificada à forma-sujeito da moral tradicional, ao que é "correto" aos olhos dos valores (cristãos) vigentes na sociedade.

Tendo em vista o caráter ambíguo de uma FD, dessa maneira, o sujeito pode ocupar diversas outras posições-sujeito dentro dela, refletindo a sua tomada de posição em relação à forma-sujeito do discurso, de acordo com diferentes níveis de identificação aos sentidos dominantes da FD que são classificados em três modalidades: o sujeito identificado, contraidentificado e desidentificado.

Assim, essa caracterização da personagem favorece nossa interpretação ao colocá-la na PS1 - sacrifício aos costumes, em que sua aparência (vestes, fisionomia, postura) refletem um comportamento recatado, contido, de uma mulher que se assujeita ao imaginário sobre a moral feminina (e também enquanto uma mulher trabalhadora, criada, servil) de seu tempo, em um nível pleno de assujeitamento.

A postura cativa da protagonista que nos dedicamos aqui a atestar, pode ser percebida em outras passagens durante o filme - sua jornada de boa Grace é extensa, mesmo frente às diversas humilhações a que é submetida. Uma dessas passagens, entretanto, é capaz retratar o ápice de sua postura valorativa, quando, em conversa com seu pai, pede que ele perdoe as pessoas de Dogville (o perdão é um saber dominante no interior da FD moral tradicional).

Essa cena se passa dentro do carro, após Tom telefonar para os gângsteres e denunciar o esconderijo de Grace. Para surpresa do espectador, o chefe da organização é seu pai, que em conversa com a filha, pede que dê um castigo a seus carrascos. Ao ser confrontada por ele, a jovem declara seu pedido de misericórdia frente às falhas daqueles que a fizeram sofrer:

SD3: (Grace) Por que não devo ser misericordiosa? 
O pai espanta-se com esse pedido, que não veio de maneira gratuita: mesmo diante de todos os abusos sofridos, Grace não reagiu. Não revidou, reclamou, tampouco tentou livrar-se do sofrimento. Ao defender ao pai seu pedido de misericórdia, manifesta um dos valores morais mais apregoados pelo cristianismo, um dos maiores alvos da crítica de Nietzsche e também um saber caro à FD de moral tradicional: a compaixão. Para o filósofo (1996), a compaixão é um dos "sentimentos elevados" mais nocivos, que tira do homem o poder.

Refere ele (1996, p.30) que "com a compaixão aumenta o sofrimento e ainda se multiplica a perda de força que prejudica a vida". É esse sentimento que coloca Grace em posição de não reação. É o valor que faz dela um sacrifício, inquestionável espírito cativo.

A compaixão é mais do que um valor que se mantém por hábito. É algo desejado socialmente e bem visto pelas pessoas: só as pessoas realmente "boas" se compadecem diante da dor alheia. Essas pessoas - tanto as que sentem compaixão pelo outro como as que manifestam sua dor, necessitando da piedade alheia - na visão do filósofo, são infelizes.

Para Nietzsche (2005, p.51) "o infeliz obtém uma espécie de prazer com o sentimento de superioridade que a demonstração de compaixão lhe traz à consciência; (...) De modo que a sede de compaixão é uma sede de gozo de si mesmo, e isso à custa do próximo". Esse é o valor que Grace invoca ao revelar ao pai que deseja ser misericordiosa e perdoar aqueles seres humanos que, nas palavras dela, fizeram o melhor que podiam sob difíceis circunstâncias.Grace se coloca, dessa maneira, como um ser "mais moral", como refere Nietzsche. Para o filósofo (2013, p.36), o ser mais moral é aquele que "em primeiro lugar cumpre a lei com mais frequência (...). Em seguida, aquele que cumpre a lei também nos casos mais difíceis. O mais moral é aquele que mais sacrifica aos costumes". A protagonista se martiriza para manter-se honesta, mesmo quando abusada, humilhada e escravizada, pois como refere Mangabeira (2012, p.163) ela "(...) não permitia castigos aos outros por se considerar num padrão moral tão elevado, que a cidade, talvez, nunca conseguiria alcançar, onde só importava o perdão e o amor ao próximo (...)".

A jovem apresenta esse comportamento cristão acentuado, torturando-se em favor de "sua" ética, mesmo quando seria aceitável flexibilizar seu posicionamento. A partir do momento que começa a ser explorada pelos dogvillianos, havia a opção de entregar-se ao pai ou à polícia, impedindo os abusos daquelas pessoas e até mesmo provocando a eles castigos pelas mãos da organização criminosa. 
Para Harres (2013, p.39) "em alguma medida, essa característica a faz cúmplice dos abusos que sofre, pois se recusa a defender-se mesmo verbalmente e tampouco revidar fisicamente. Grace possui uma predisposição ao martírio". Por isso, a boa Grace, diante do seu assujeitamento à FD, "prefere" resignar-se e sofrer nas mãos de seus carrascos. De acordo com Nietzsche (2005, p.74), buscar um revide na posição em que a mulher se encontrava, não seria uma atitude imoral: "causar dano intencionalmente, quando está em jogo nossa existência ou segurança (conservação de nosso bem-estar), é admitido como sendo moral", ou seja, ela não estaria indo contra os costumes ao tentar preservar-se.

Ela faz mais do que manter-se otimista frente às contrariedades: ela suporta as torturas, diante de pouca luta e pouca resistência. Há um sentido de servidão em seu posicionamento, uma entrega de quem "prefere" ser torturada a ter que voltar para o lado do pai criminoso (uma "opção" de ordem moral, que prefere ser a vítima do que malfeitora). Tal atitude estoica, ética e preocupada com seus princípios, não é algo comum na cidade de Dogville e tampouco na sociedade em geral.

No máximo dos valores cristãos, Grace (a graça de Dogville) pode representar o próprio Cristo. Esse Jesus é aquele que pede a Deus para que perdoe seus carrascos quando crucificado, pois, eles como animais que são, não tem entendimento de suas atitudes. Um Cristo feminino, servil, que foge de seu pai poderoso que o quer junto dele. Um Cristo de moral elevada, que, embora em um corpo humano, é figura divina e entende a natureza (instinto) dos animais.

Nietzsche considera, ao tratar do cristianismo, que só existiu um cristão no mundo: aquele que morreu na cruz. Para o filósofo $(1996$, p.91) "(...) somente a prática cristã, uma vida como a dele, que morreu na cruz, é cristã... Ainda hoje uma vida assim é possível, para alguns homens até necessária". Grace busca essa vida redentora ao fugir de uma realidade de crimes e entrega-se à sua cruz.

A partir do desfecho do filme, o Cristo subversivo de Dogville, ao contrário de ser crucificado, compreende a sua arrogância e busca um novo destino - essas pessoas, as quais não foram boas o suficiente, merecem a compensação por seus atos, merecem ser julgadas. Dogville precisa ser corrigida, e, como refere seu narrador, "se alguém tivesse o poder de consertar as coisas, esse alguém teria a obrigação de fazê-lo". E assim, ao final, Grace desliza de sua posição-sujeito e apresenta outra modalidade de tomada de posição em relação aos saber da forma-sujeito da FD. Revela, assim, um "afastamento" do espírito cativo 
nietzschiano, embora ainda muito longe de uma transvaloração dos valores, situação desejada pelo filósofo para a humanidade.

\subsection{A SUBVERSIVA GRACE NO DISCURSO FÍLMICO DE DOGVILLE}

A partir da conversa com o pai, em que ele a acusa de arrogância e de padrões éticos elevados por querer perdoar as pessoas que lhe fizeram mal, a "graça de Dogville" movimenta o sentido do seu discurso dentro da FD de moral tradicional e desliza de sua posição-sujeito plenamente identificada (PS1 - sacrifício aos costumes). Isso é possível dada a heterogeneidade da FD, que abriga a diferença e a divergência, e também ao sujeito cindido e em conflito, que pode se relacionar à forma-sujeito em diferentes níveis de identificação, conforme refere Santos Neto (2015, p.102):

No movimento de sentidos de identificação e contra-identificação, pode haver negociação, produzindo um deslocamento de posição-sujeito. Em outras palavras, a ideologia jamais se ausenta, pelo contrário, apenas interage de outra forma, mas mantendo o domínio do saber universal da formação discursiva dominante.

SD4: (Grace) E isso significa que eu assumirei a responsabilidade imediatamente. Eu seria parte da solução deste problema. O problema "Dogville".

SD5: (Grace) Quero fazer deste mundo um lugar melhor.

Assim, o carrasco de Dogville age de maneira imprevista ao solicitar ao pai a sentença da cidade, em que decide que exterminá-la pode fazer do mundo um lugar melhor. Embora com essa mudança brusca em sua tomada de posição, Grace não se desidentifica à FD da moral tradicional, o que pode ser afirmado diante da necessidade da mulher em justificar sua escolha: não remete a vontade de acabar com a cidade a um ato de vingança ou algo motivado pelo ódio. Menos ainda, refere que essa sentença seja uma pena a eles aplicada.

O motivo que Grace dá para sua escolha é "fazer do mundo um lugar melhor", ou seja, exterminar Dogville visando o bem da humanidade e de qualquer pessoa que pudesse passar pela cidade e sofrer os mesmos abusos que ela sofreu. Dessa maneira, ainda que comande o homicídio de várias pessoas, cometendo um ato de imoralidade (que vai contra seu ser "mais moral") e acima disso, um ato criminoso, usa de uma justificativa moral para pautar sua decisão, como se alegasse que o sacrifício de alguns é para um bem maior. 
E Grace, apesar de permanecer na FD da moral tradicional, se entrega à imoralidade (que pode ter esse sentido de "tolerada socialmente") e desliza de sua posição-sujeito plenamente identificada para uma posição contra-identificada a dada FD. A essa nova posição-sujeito de Grace denominamos PS2 - imoralidade justificada.

A começar por seu relacionamento com os valores: sua súbita mudança de opinião é o que surpreende, visto que ela passa de um "mártir", alguém dotada de misericórdia, compaixão, esperanças e que só vê o lado bom das pessoas e se sacrifica por seus valores, para alguém que assina suas sentenças de morte. Essa oscilação em seu posicionamento é muito rápida no filme, e isso nos faz contrapor com facilidade seu comportamento anterior à sua decisão, ocasionando a percepção de que ela se torna alguém cruel. Entretanto, Grace dá seu veredito partindo, ainda, de valores morais. Não há um rompimento com as normas sociais, um imperativo de transvaloração dos costumes ou o reflexo de uma mudança interior - ela alega que estaria fazendo um bem para a humanidade ao eliminar Dogville. Harres (2013, p.40) certifica essa leitura, alegando que "nesse último momento, Grace toma a resolução que entende como seu novo dever moral: executar a justiça com o poder que tem".

Há nesse discurso o reflexo de sua ética superior, tanto quando refere que "eu serei parte da solução desse problema", como quando diz "quero fazer desse mundo um lugar melhor". Por mais que sua postura submissa, de sacrifícios, dê lugar a alguém que demanda poder, é como se Grace sentisse o dever, como um ser "mais moral", de fazer a justiça.

Há também um afastamento parcial de Grace ao espírito cativo nietzschiano. Embora não deixe de comportar-se como um (por seu relacionamento com os valores, ainda presente no discurso da protagonista), ela já não se caracteriza tanto como um ser do rebanho mediante suas escolhas questionáveis, embora as justifique como um "mal necessário", ou algo com um propósito maior. Como alega Nietzsche (1998), o bom, aos olhos da moralidade dos costumes é aquele que não fere, não ataca, não vinga, que foge da maldade - atitudes das quais Grace se desviou ao solicitar o massacre.

Dois momentos no discurso fílmico, no entanto, nos fazem duvidar dessa relação de Grace com a FD de moral tradicional. O primeiro (SD6) é quando ela solicita aos gângsteres que atirem nos filhos de Vera na frente da mulher, um a um, para que ela chore. Esse pedido acontece por um revide: Vera quebrou os bonecos de porcelana da jovem, prometendo que pararia somente se ela não chorasse. Assim, a fugitiva alega que "deve isso à mulher". O outro é quando a protagonista pega a arma do pai e atira em Tom, afirmando que "há coisas que temos que fazer pessoalmente" (figura 1). 
SD6: (Grace) Há uma família com filhos. Mate os filhos primeiro e faça a mãe olhar.

Diga que só vai parar se ela não chorar. Eu devo isso a ela.

Figura 1 - Grace atira em Tom

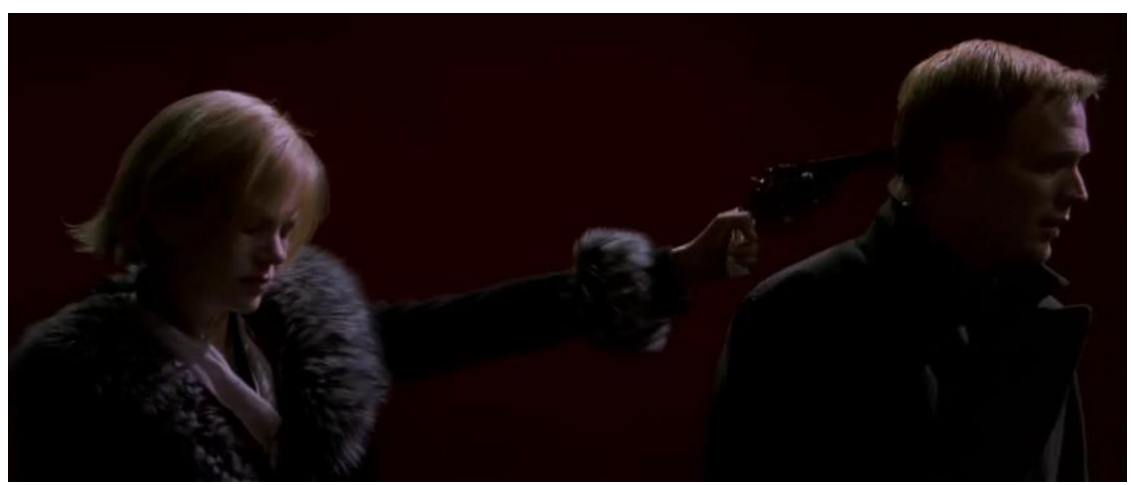

Fonte: Dogville, 2003. DVD (177min).

Nesse sentido, alguns autores referem a decisão de Grace como um ato de vingança (não só a partir desses dois momentos, mas todo o acontecimento final), como é o caso de Gerace (2011, p.84). Ele alega que, diante do não reconhecimento do Bem pelos habitantes da cidade, a protagonista "decide conter o Mal pagando na mesma moeda, mostrando sua face terrível, como o Deus do Velho Testamento em Sodoma e Gomorra". Para Mangabeira (2012), há prazer na atitude de Grace a partir de sua reflexão sobre a impossibilidade de cumprir os mandamentos éticos cristãos diante do que passou.

Mas esses dois momentos, em especial, acrescentam à imoralidade de Grace requintes de crueldade. São duas tomadas de posição da protagonista que não apresentam razões essencialmente morais, de "tornar o mundo um lugar melhor", mas beiram à represália, a dar o troco na mulher que a fez chorar por bonecos de porcelana e no homem que declarou a ela seu amor, mas que como um Judas, a traiu.

Pautados nesses dois atos, podemos alegar que há uma sutil movimentação de Grace para outra posição-sujeito, pela qual não há mais justificativas ou valores superiores, mas sim a frieza da retaliação. A essa posição-sujeito chamamos de PS3 - vislumbre de crueldade, da qual a jovem se entrega momentaneamente, logo retomando sua feição de piedade, suas justificativas e sua imoralidade justificada da PS2. Nessa movimentação, ao deslizar para a PS3, Grace se contra-identifica à forma-sujeito da FD em seu maior nível de contraidentificação e em um alto grau de reversibilidade a essa forma-sujeito, podendo, a qualquer momento, desidentificar-se à FD de moral tradicional. 


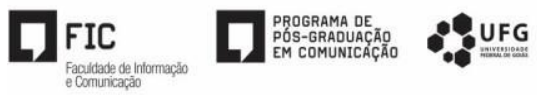

Defendemos, no entanto, que por serem momentos curtos em que ela desliza para a PS3, novamente retomando a posição anterior, ela ainda não deixa a FD a qual se assujeita, mas encontra-se em vias de, para quem sabe, em sua próxima saga (filme Manderlay, na sequência), desidentificar-se, tangibilizando e potencializando as desordens morais e o deslizamento de sentido em uma FD de moral tradicional.

\section{CONSIDERAÇÕES FINAIS}

Ao analisar, neste artigo, algumas materialidades fílmicas de Dogville visando entender a aproximação entre o discurso moral da obra e as considerações nietzschianas, tendo em vista o comportamento da personagem Grace no discurso fílmico, estabelecemos que a narrativa é um palco de desordens morais. Seja por meio das cenas ou das sequências discursivas, a tomada de posição da protagonista em relação à FD da moral tradicional é constitutiva desses conflitos entre os valores hegemônicos da sociedade, entre o que pode ou deve ser dito a respeito deles e às atitudes, ora cativas, ora perversas, da mulher.

Ao levar em consideração a noção cinematográfica de modos de endereçamento, temos que os filmes (e outras obras) são destinados para alguém, para um público imaginado, como se fossem feitos sob medida para sujeitos em uma dada posição (ELLSWORTH, 2011). Esse espectador "projetado", pensado para o filme, é aquele do qual são derivadas as posições-sujeito dos personagens, que podem ser incorporadas pelo espectador real (o que realmente consome o discurso fílmico). Dessa maneira, ele (espectador real) pode incorporar as posições-sujeito de Grace, e também a ambiguidade que elas apresentam. Temos, assim, que as narrativas (aqui a cinematográfica) são construídas visando uma representação do sujeito da "realidade", ou seja, o espectador, que vai se identificar e se reconhecer na história e nos personagens.

Tal espelhamento, possibilitado por essa projeção do diretor acerca do público, é uma das propriedades do cinema que o certificam como um importante objeto de estudo no campo da comunicação: pelo imaginário do autor do discurso (nesse caso, von Trier) sobre a sociedade, sobre o ser humano e sobre o leitor de sua obra, a narrativa visa retratar os conflitos da existência, da contemporaneidade, aproximando Grace (e os demais habitantes de Dogville) de quem está na poltrona do cinema consumindo o discurso fílmico.

Assim, personagens em conflito, controversos, ambíguos em relação à moral, refletem o imaginário do diretor sobre seu espectador, incidindo, nessa aproximação, em uma 
"incorporação" das posições-sujeito apresentadas na história. O espectador que é imaginado acaba por incorporar, dessa maneira, também a ambiguidade que a narrativa apresenta, a controvérsia, a contradição de quem ora apresentou uma tomada de posição, ora deslizou para outra PS em outra tomada de posição. São esses deslizamentos que refletem a complexidade do próprio ser humano, materializada no filme por meio dos sujeitos da história, e projetada pelo diretor para seu público. As desordens morais são o reflexo desse sujeito fragmentado que o diretor imagina, que ele próprio o é, que materializa em seus personagens e que nós leitores reais, analistas, espectadores - também o somos.

Os questionamentos de Nietzsche acerca da validade dos valores morais, dado seu caráter temporal e de "licença" que apresentam, podem ser ilustrados pelo discurso fílmico de Dogville e pela análise das desordens morais de Grace apresentadas neste artigo. Que benefícios tem o ser humano ao sucumbir a valores que cativam seu espírito animal? Qual a legitimidade de um código moral que se molda às circunstâncias, a quem o pratica, às desculpas que são dadas em seu nome? A protagonista pouco se questionava sobre a necessidade de sua submissão, e posteriormente, à necessidade de seu pedido de destruição. No entanto, suas atitudes pautaram-se em justificativas e em "deveres" que considerava como seus - suas ações, foram, no fundo, reações, típicas de uma moral escrava, de "rebanho".

Pautados nesses valores que o espectador pode "reconhecer" em Grace, principalmente na "boa Grace", é fácil uma identificação deste com a protagonista (se não uma identificação, ao menos uma "apreciação" do seu comportamento ético inatingível, pouco comum na sociedade). Dessa maneira, ao propiciar as desordens morais e deslizar o sentido do seu discurso (mudando sua tomada de posição), a personagem expõe o sujeito ambíguo, em conflito, que tensiona os saberes de uma FD, constituindo o ser da pós-modernidade.

Ao desafiar o tradicional, o discurso de Grace indica o que parece ser uma das principais contribuições do filme: desestabilizar discursos que parecem sólidos, estabelecidos, causando mal-estar frente a essa desestrutura. Principalmente pelo vínculo que estabelecemos com a narrativa, seja pela familiaridade da história, do contexto, da situação, seja pelas posições-sujeito da protagonista que, ao refletir o espectador e revelar sua ambiguidade, podem causar fácil proximidade e identificação.

Ao nos aproximarmos de Grace ou dos demais dogvillianos, os questionamentos se intensificam: como agiríamos se morássemos em alguma daquelas casas miseráveis, se sofrêssemos as torturas imputadas à Grace, se detivéssemos o poder do gângster? E nessa "balança" moral que é Dogville, da qual tem, inicialmente, a protagonista 
"contrapesando" todas as imoralidades do filme, como a vemos em seu final? Ainda justa, equilibrada, ou pendente totalmente ao lado transgressor?

Assim é o sujeito da AD: fragmentado, contraditório, limítrofe. Assim é o sujeito contemporâneo, da pós-modernidade, que vive em desestabilidade, em conflito, reorganizando saberes. Esse sujeito incorpora as desordens morais: esses deslizamentos de sentido que a moral pode ter dentro de sua instituição, uma heterogeneidade controversa que é legitimada socialmente. A compaixão, a culpa, o perdão, o abuso sexual, o homicídio saberes divergentes, que reafirmam e transgridem os valores, mas que se pautam em uma mesma formação ideológica de obediência aos costumes.

Dogville nos apresenta esse espaço para uma reflexão nietzschiana sobre os valores, baseada nas desordens morais do discurso fílmico: em um cenário de ambiguidade como o representado na narrativa e como o que vivenciamos na contemporaneidade, qual a necessidade e legitimidade de regras sociais preestabelecidas? O prazer e o conforto que o "certo/errado", "bem/mal" nos proporciona, é compatível a um cenário divergente, como o que é apresentado no filme? E por fim, se assumimos o conflito que nos constitui, o equívoco a que nos entregamos, a ambiguidade que nos é inerente, o quanto viver por hábitos e costumes não revela nossa "dissimulação" moral? O filósofo, no século XIX, indagava-se constantemente sobre tais incoerências; von Trier dá vida a elas em seu discurso fílmico. Cabe também a nós - espectadores, comunicadores, analistas do discurso - refletir sobre tais desordens que revelam a fragilidade da instituição moral.

\section{REFERÊNCIAS}

DOGVILLE. Direção de Lars von Trier. Produção de Vibeke Windelov. França (lançamento): Zentropa Entertainments, 2003. 1 DVD (177 min).

ELLSWORTH, E. Modos de endereçamento: uma coisa de cinema; uma coisa de educação também. In: SILVA, T. T. (org.). Nunca fomos humanos: nos rastros do sujeito. Belo Horizonte: Autêntica, 2001.

FERREIRA, M. C. L. Análise de Discurso e Psicanálise: Uma estranha Intimidade. Caderno da APPOA, n.131, p.37-52, dez/2004.

GERACE, R. Intermidialidade em Dogville. Pós: Revista do Programa de Pós-graduação em Artes da EBA/UFMG, Belo Horizonte, v. 1, n. 2, p.75-87, nov. 2011. 
HARRES, P. M. Ilustração e meta-ética em Dogville. Trabalho de Graduação (Bacharelado em Filosofia). 61f. Instituto de Filosofia e Ciências Humanas, Universidade Federal do Rio Grande do Sul, Porto Alegre, 2013.

INDURSKY, F. A fala dos quartéis e outras vozes. 2.ed. Campinas: Editora da Unicamp, 2013.

MANGABEIRA, C. Olhando para trás ou para que serve um filme de 2003? Uma análise sociológica de Dogville. Áskesis, v.1, n.1, p.142-165, jan./jul. 2012. Disponível em: <https://revistaaskesis.files.wordpress.com/2012/04/revista-askesis-ensaio02_p142-165.pdf>. Acesso em 30 mar. 2017.

NIETZSCHE, F. W. O Anticristo: maldição do cristianismo. Rio de Janeiro: Clássicos Econômicos Newton. 1996.

NIETZSCHE, F. W. Genealogia da Moral: uma polêmica. São Paulo: Companhia das Letras, 1998.

NIETZSCHE, F W. Humano, demasiado humano: um livro para espíritos livres. São Paulo: Companhia das Letras, 2005.

NIETZSCHE, F. W. Aurora. São Paulo: Escala, 2013.

ORLANDI, E. P. Análise de discurso: princípios e procedimentos. 12.ed. Campinas: Pontes Editores, 2015.

SANTOS NETO, H. I. C. Análise do discurso radiofônico: o acontecimento apagão em Florianópolis. 291f. Tese (Doutorado em Ciências da Linguagem) - Universidade do Sul de Santa Catarina, Palhoça, 2015. 